\title{
Tubular Electrospun Vancomycin-Loaded Vascular Grafts: Formulation Study and Physicochemical Characterization
}

\author{
Rossella Dorati ${ }^{1, *(\mathbb{C})}$, Enrica Chiesa ${ }^{1}$, Mariella Rosalia ${ }^{1}$, Silvia Pisani ${ }^{2}$, Ida Genta ${ }^{1}\left(\mathbb{D}\right.$, Giovanna Bruni $^{3}{ }^{\circledR}$, \\ Tiziana Modena ${ }^{1}$ and Bice Conti ${ }^{1}{ }^{1}$ \\ 1 Department of Drug Sciences, University of Pavia, Via Taramelli 12, 27100 Pavia, Italy; \\ enrica.chiesa@unipv.it (E.C.); mariella.rosalia01@universitadipavia.it (M.R.); ida.genta@unipv.it (I.G.); \\ tiziana.modena@unipv.it (T.M.); bice.conti@unipv.it (B.C.) \\ 2 Immunology and Transplantation Laboratory, Pediatric Hematology Oncology Unit, \\ Department of Maternal and Children's Health, Fondazione IRCCS Policlinico S. Matteo, 27100 Pavia, Italy; \\ silvia.pisani01@universitadipavia.it \\ 3 Department of Chemistry, Physical Chemistry Section, University of Pavia, Via Taramelli 12, \\ 27100 Pavia, Italy; giovanna.bruni@unipv.it \\ * Correspondence: rossella.dorati@unipv.it; Tel.: +39-0382-987393
}

check for updates

Citation: Dorati, R.; Chiesa, E.; Rosalia, M.; Pisani, S.; Genta, I.; Bruni, G.; Modena, T.; Conti, B. Tubular Electrospun Vancomycin-Loaded Vascular Grafts: Formulation Study and Physicochemical Characterization. Polymers 2021, 13 2073. https://doi.org/10.3390/ polym13132073

Academic Editor: Pierangiola Bracco

Received: 27 May 2021

Accepted: 18 June 2021

Published: 24 June 2021

Publisher's Note: MDPI stays neutral with regard to jurisdictional claims in published maps and institutional affiliations.

Copyright: (C) 2021 by the authors. Licensee MDPI, Basel, Switzerland. This article is an open access article distributed under the terms and conditions of the Creative Commons Attribution (CC BY) license (https:/ / creativecommons.org/licenses/by/ $4.0 /$ )

\begin{abstract}
This work aimed at formulating tubular grafts electrospun with a size $<6 \mathrm{~mm}$ and incorporating vancomycin as an antimicrobial agent. Compared to other papers, the present study succeeded in using medical healthcare-grade polymers and solvents permitted by ICH Topic Q3C (R4). Vancomycin (VMC) was incorporated into polyester synthetic polymers (poly-L-lactide-co-poly$\varepsilon$-caprolactone and poly lactide-co-glycolide) using permitted solvents; moreover, a surfactant was added to the formulation in order to avoid the precipitation of VMC on fiber surface. A preliminary preformulation study was carried out to evaluate solubility of VMC in different aqueous and organic solvents and its stability. To reduce size of fibers and their orientation, we studied a solvent system based on methylene chloride and acetone (DCM/acetone), at different ratios (80:20, 70:30, and 60:40). Considering conductivity of solutions and their spinnability, solvent system at a 80:20 ratio was selected for the study. SEM images demonstrated that size of fibers, their distribution, and their orientation were affected by the incorporation of VMC and surfactant into polymer solution. Surfactant allowed for the reduction of precipitates of VMC on fiber surface, which are responsible of the high burst release in the first six hours; the release was mainly dependent on graft structure porosity, number of pores, and graft absorbent capability. A controlled release of VMC was achieved, covering a period from 96 to $168 \mathrm{~h}$ as a function of composition and structure; the concentration of VMC was significantly beyond VMC minimum inhibitory concentration (MIC, $2 \mathrm{ug} / \mathrm{mL}$ ). These results indicated that the VMC tubular electrospun grafts not only controlled the local release of VMC, but also avoided onset of antibiotic resistance.
\end{abstract}

Keywords: vessel; tubular graft; electrospinning; vancomycin

\section{Introduction}

The present research study was planned for designing, producing, and characterizing electrospun tubular grafts with diameter $<6 \mathrm{~mm}$ made of biodegradable polymer fibers and loaded with an antimicrobial drug, vancomycin (VMC). The success of these electrospun polymer tubular grafts would offer a valuable resource for treating coronary artery diseases and peripheral vascular disease, which very commonly require the transplant of native damaged blood vessel. The currently available options for blood vessel transplant are numerous (allografts, autologous grafts, xenografts, artificial prostheses, or inert vascular graft) and they were successfully applied to replace large diameter blood vessels; nevertheless, they usually fail when used for replacing small diameter blood vessels as reported in the literature and the scientific research running in this field [1-12]. 
Moreover, infections arising after surgery are a frequent problem that need to be faced as they are becoming a severe problem, as well as the problem of antibiotic resistance [13]. Combining an antibiotic drug to the electrospun polymer tubular vascular graft would provide protection from rising infection after implant surgery, while also reducing systemic administration of an antibiotic, thus monitoring its known side effects and antibiotic resistance phenomenon [14-16].

Our hypothesis was that the VMC-loaded tubular vascular graft (VTVG) based on electrospun nanofiber should offer an alternative approach in the field of tissue engineering for implementing engineered vascular graft. Moreover, the electrospinning technique exploited for obtained fiber texture should strengthen both the vascular graft production in terms of reproducibility and repeatability and implement their in vivo performances. The proposed tubular graft should meet some of the artificial vessel requirements: (i) biocompatibility and biodegradability, (ii) possession of mechanical features allowing surgical manipulation and bearing prolonged hydrodynamic loading, and (iii) provision of suitable structural properties for cell attachment and growth.

Electrospinning is an innovative technique whose usefulness has increased in recent years due to the method simplicity reproducibility and scalability. Electrospinning is a technique used to produce nanoscale and microscale polymer fibers through the application of an electric current to a polymer solution. The instrument set up provided with a rotating mandrel collector allows us to manufacture tubular polymer matrices of the desired diameter. Moreover, fiber orientation may be adjusted in order to obtain tubular grafts with oriented fibers, improving mechanical stretching properties. The technique is particularly attractive for the production of much smaller diameter fibers; small-diameter tubular grafts result in a prototype with a high surface area, porosity, and an interconnected and even oriented three-dimensional network structure. Moreover, they more closely mimic natural blood vessels' skeleton structure compared with the tubular scaffold prepared by conventional methods [17-21]. There are some fundamental parameters that have to be taken in consideration to set up a correct electrospinning procedure, i.e., the polymer solution properties and the instrument settings as flow rate, applied electrical potential, working distance, mandrel's rotation speed, spinneret's width and speed, humidity, and temperature. Solution and instrument parameters are fundamental to define products' final characteristics (mechanical properties, porosity, pore size distribution, morphology, and nanofiber diameter). All these parameters depend on the polymer or polymer blends chosen to make the tubular grafts, with these having been studied by authors in previous works [15,22-24]. Starting from the previous collected data, polylactide-co-glycolide (PLGA) and polylactideco-polycaprolactone (PLA-PCL) were chosen to prepare the tubular vascular grafts loaded with an antibiotic drug.

VMC has been chosen in this study for loading into the electrospun tubular vascular grafts because it is active against methicillin-resistant Staphylococcus aureus (MRSA) and methicillin-resistant Staphylococcus epidermidis (MRSE) that are very common in the skin flora, being the most common pathogens thought to be inoculated directly into the wound during surgery. These species are increasingly resistant to cephalosporin used for routine preoperative prophylaxis. Instead, a $2.4 \%$ reduction in the rate of surgical site infections (SSI) has been reported with the addiction of topical vancomycin after elective spine surgery [25]. VMC is one of the oldest antibiotics in clinical use for more than 60 years. The tricyclic glycopeptide structure consists of seven membered peptide chains and attached disaccharide composed of vancosamine and glucose; its molecular weight is higher than most $\beta$-lactam antibiotics. It inhibits cell wall synthesis in its later stages, thus affecting dividing bacteria. The target of its activity, its mechanism of action, and it site adverse effects are well known, having been recently revisited by Rubinstein and colleagues [26].

VMC is active against Gram-positive aerobic cocci and bacilli, e.g., Staphylococci, Streptococci, Enterococci, and Pneumococci, as well as Corynebacterium; Listeria; Bacillus spp.; Clostridia; oral Gram-positive anaerobes; and strains of Leuconostoc, Lactobacillus, and Pediococcus. The antibiotic drug was normally administered intravenously, with a standard 
infusion time of at least $1 \mathrm{~h}$ in order to minimize infusion-related adverse effects. It has an $\alpha$-distribution phase of about $30 \mathrm{~min}$ to $1 \mathrm{~h}$ and a $\beta$-elimination half-life of $6-12 \mathrm{~h}$ in patients with normal creatinine clearances. Its volume of distribution is $0.4-1.0 \mathrm{~L} / \mathrm{kg}$, and its binding to plasma protein ranges from 10 to $50 \%$. Instead, VMC absorption after oral administration is scarce, with $>80-90 \%$ recovered unchanged in the urine within $24 \mathrm{~h}$ after administration of a single dose. Factors that affect the overall activity of VMC include its tissue distribution, inoculum size, and protein-binding effects. Even if VMC was tolerated well with appropriate dosing, the most common side effects include thrombophlebitis, fever, rash, reversible neutropenia, and VMC-associated nephrotoxicity, reported to occur in 5 to $30 \%$ of hospitalized patients receiving intravenous vancomycin [26,27]. In particular, a study managed by Zasowski and colleagues focused on patients with bacteremia or pneumonia indication for VMC, defining that daily vancomycin AUC values between 600 and $800 \mathrm{mg} \cdot \mathrm{h} /$ liter during the first $48 \mathrm{~h}$ of therapy are associated with a three- to fourfold-increased nephrotoxicity risk. Instead, the risk of VMC-associated ototoxicity can be considered as due to carelessness according to the literature $[27,28]$.

VMC can be locally administered as powder, crystallized as a salt with hydrochloride, or conveyed in antibiotic-impregnated biodegradable grafts [25,29,30]. Electrospun meshes can act as local drug delivery systems. Liu et al. developed a nanofiber vascular prosthetic graft containing VMC that was the standpoint for our investigation, taking into consideration specific technological aspects including product safety, quality, and efficacy [2]. Tseng and colleagues studied antibiotic-loaded biodegradable polylactide-co-glycolide (PLGA) nanofiber membranes for sustainable delivery of VMC to the brain tissue of rats and their experimental results, suggesting that the biodegradable nanofibers release high concentrations of VMC for more than 8 weeks in the cerebral cavity of rats without inflammation reaction of the brain tissues. Jang and colleagues demonstrated that electrospun VMCeluting polycaprolactone/poly ethylene oxide/VMC (PCL/(PEO/VM)/PCL) nanofiber matrices promoted extended release of antibiotic locally with higher effective antibiotic concentrations avoiding potentially toxic VMC systemic concentrations; moreover, they are good candidates for prevention of periprosthetic MRSA infection and biofilm formation. The latter was known to be hardly eradicated through administration of conventional systemic antibiotic therapy.

Starting from the literature, VMC-eluting electrospun polymer nanofibers can be considered promising candidates of sustained drug delivery systems, with the present study aiming to design and formulate VTVGs.

\section{Materials and Methods}

\subsection{Materials}

Poly-L-lactide-co-poly- $\varepsilon$-caprolactone (PLA-PCL) 70:30, Resomer LC 703 S, Mw 160 kDa, $\mathrm{Tg} 37^{\circ} \mathrm{C}$ and poly lactide-co-glycolide (PLGA) 82:18, Resomer LG 824 S, Mw $33.4 \mathrm{kDa}, \mathrm{Tg}$ 54-60 ${ }^{\circ} \mathrm{C}$ were from Evonik Nutrition and Care (GmbH, 64275 Damstad, Germany). Vancomycin hydrochloride from Streptomyces orientalis $\left(\mathrm{C}_{66} \mathrm{H}_{75} \mathrm{C}_{12} \mathrm{~N}_{9} \mathrm{O}_{24}, \mathrm{HCl}\right), \mathrm{Mw} 1485.71 \mathrm{Da}$ potency $\geq 900 \mu \mathrm{g}$ per mg (as VMC base); $\operatorname{Span}^{\circledR} 80$; nonionic surfactant (sorbitan monooleate, sorbitan oleate); ammonium phosphate monobasic $\left(\mathrm{NH}_{4} \mathrm{H}_{2} \mathrm{PO}_{4}\right)$ analytical grade $\geq 98.0 \%$, Mw $115.03 \mathrm{Da}, 1.81 \mathrm{~g} / \mathrm{cm}^{3}$; methanol $\left(\mathrm{MeOH}, \mathrm{CH}_{3} \mathrm{OH}\right)$ analytical grade $\geq 99.9 \%$, Mw 32.04 Da; N,N-dimethylformamide (DMF, $\mathrm{C}_{3} \mathrm{H}_{7} \mathrm{NO}$ ) analytical grade 99.8\%, Mw 73.09 Da; phosphate-buffered saline tablet (PBS); phosphoric acid $\left(\mathrm{H}_{3} \mathrm{PO}_{4}\right)$ analytical grade $\geq 85 \%$, Mw 98 Da; and sodium azide $\left(\mathrm{N}_{3} \mathrm{Na}\right) \mathrm{Mw}$ 65.01 Da were from Sigma-Aldrich (Milano MI, Italy). Acetone $\left(\mathrm{CH}_{3} \mathrm{COCH}_{3}\right)$, analytical grade $99.8 \%$, Mw 58.01 Da; chloroform (CHL, $\mathrm{CHCl}_{3}$ ) analytical grade $99.9 \%$, Mw $119.38 \mathrm{Da}$; and dichloromethane (DCM, $\mathrm{CH}_{2} \mathrm{Cl}_{2}$ ), analytical grade 99.9\%, Mw 84.93 Da, were from Carlo Erba (Carlo Erba SpA, Milano, Italy). Acetonitrile $\left(\mathrm{CH}_{3} \mathrm{CN}\right) \mathrm{Mw} 41.05$ Da was from Merck (Darmstadt, Germany). In-house double-distilled water was filtered with $0.22 \mu \mathrm{m}$ Millipore membrane filters before use (Millipore Corporation, Bedford, MA, USA). 


\subsection{Methods}

\subsubsection{Preformulation Study}

Solubility of Vancomycin in Organic and Aqueous Phase

VMC solubility was assayed in different solvents: DCM, acetone, methanol, water, PBS (pH 7.4), and solvent system based on DCM: acetone (70:30). VMC powder weighing was carried out in a glovebox (Unilab- 2000, MBRAUN GmbH Dieselstrasse 31, 85748 Garching/Munchen) because of its sensibility to humidity and its cytotoxicity. MBraun Glovebox System is a controlled, inert environment workspace with a nitrogen atmosphere and a rated specification of $<1 \mathrm{ppm} \mathrm{O}_{2}$. The system has several antechambers for quick sample insertion and removal, and it contains a built-in three-source thermal evaporator deposition system and a basic spin coating system.

The test was performed by placing VMC powder into a vial, and by adding $10 \mathrm{~mL}$ of solvent, the system was kept in water ice batch under magnetic stirring for a time sufficiently long enough to reach equilibrium. Samples were prepared and analyzed as described below. The solutions were analyzed by HPLC (described below) upon proper dilution at $15 \mu \mathrm{g} / \mathrm{mL}$ (Figure 1). All experiments were carried out in triplicate.
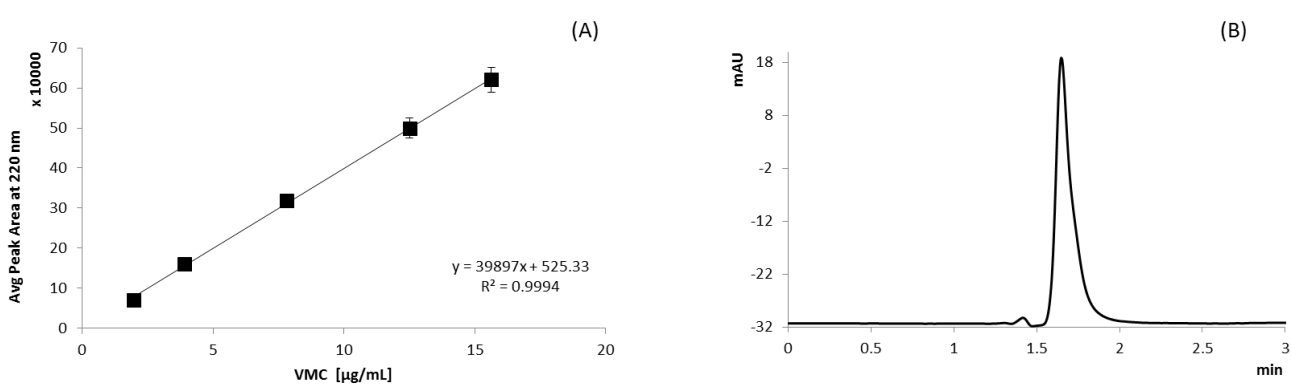

Figure 1. Calibration curve of VMC solutions of different concentrations $(1.95-15.63 \mu \mathrm{g} / \mathrm{mL})$ measured at $220 \mathrm{~nm}(\mathbf{A})$, HPLC chromatogram of VMC standard solution in DI water $(0.5 \mu \mathrm{g} / \mathrm{mL})(\mathbf{B})$.

Stability of Vancomycin in Organic and Aqueous Phase

Stability of VMC in liquid state was estimated at refrigerated temperature, $22{ }^{\circ} \mathrm{C}$, to assess the best conditions for the storage and in vitro studies. Briefly, a weighed amount of VMC was dissolved in $\mathrm{H}_{2} \mathrm{O}$ and PBS, and the solutions were incubated protected from light at above temperatures for 7 days. Photo-stability study was conducted by exposing VMC solutions to visible light at the same conditions described above. Samples were withdrawn at predetermined time points, and they were submitted to high-pressure liquid chromatography (HPLC) analysis upon proper dilution. All experiments were performed in triplicate.

\subsubsection{Method of Analysis}

To quantify VMC in in organic and aqueous phase, as well as in electrospun grafts, we used HPLC and UV methods:

\section{UV Method}

The spectrophotometric $4 \mathrm{~nm}$ SBW spectrophotometer fitted with single $10 \times 10 \mathrm{~mm}$ cuvette holder (Jenway model 6705 scanning UV-visible spectrophotometer) was used for VMC quantification. VMC was determined from a standard calibration curve prepared starting from a stock solution containing $0.5 \mathrm{mg} / \mathrm{mL} \mathrm{VMC}$ in in water (Figure 1). The stock solution was diluted in a volumetric flask with deionized (DI) water to obtain solutions of $1.95,3.91,7.81,12.50$, and $15.63 \mu \mathrm{g} / \mathrm{mL}$ of VMC. Each standard solution was analyzed in triplicate, and each point of the calibration curve is the average of the three analyses. 


\section{HPLC Analysis}

VMC was quantitatively determined by HPLC analysis, and chromatographic separation was performed on column Zorbax Eclipse ${ }^{\circledR}$ Plus C18, $4.6 \times 150 \mathrm{~mm}, 5$ m equipped with a pre-column, and temperature-controlled at $22{ }^{\circ} \mathrm{C}$. VMC aqueous solution was injected through a manual injector (volume $20 \mu \mathrm{L}$, Agilent 1260 Infinity Manual Injector). The pump (1260 Infinity Quaternary Pump VL) provided a constant and continuous flow at $1.0 \mathrm{~mL} / \mathrm{min}$. The mobile phase was a mixture of $\mathrm{NH}_{4} \mathrm{H}_{2} \mathrm{PO}_{4}(0.05 \mathrm{M}, \mathrm{pH} 4.0$ adjusted with $\mathrm{H}_{3} \mathrm{PO}_{4}$ ) and $\mathrm{CH}_{3} \mathrm{CN}$ at a ratio of $92: 8$, filtered through a cellulose filter membrane (pore size $0.22 \mu \mathrm{m}$ ) and sonicated for $5 \mathrm{~min}$.

The detector (Agilent 1260 Series UV-visible detector) was set at $220 \mathrm{~nm}$, referring to previous work in the literature [31]. VMC was determined from a standard calibration curve prepared starting from a stock solution containing $2 \mathrm{mg} / \mathrm{mL}$ VMC in mobile phase (Figure 2); the stock solution was diluted in a volumetric flask with mobile phase to obtain solutions of 1.95, 3.91, 7.81, 12.50, and $15.63 \mu \mathrm{g} / \mathrm{mL}$ of VMC. Each standard solution was tested in triplicate at $217 \mathrm{~nm}$, and each point of the calibration curve is the average of the three analyses. Equation $\mathrm{y}=0.1138 \mathrm{x}-0.1319, \mathrm{R}^{2} 0.992$.
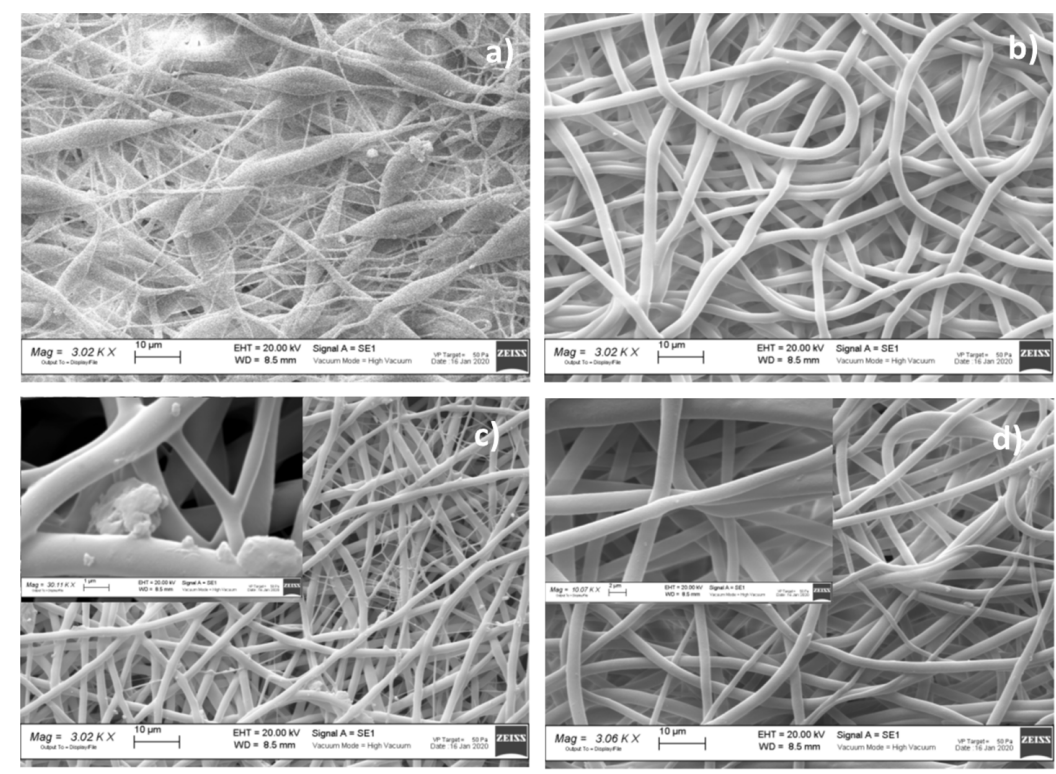

Figure 2. SEM images of (a) VTVG5; (b) VTVG6; (c) VTVG7; (d) VTVG8. Insert shows 10 kX magnification images.

\subsubsection{Polymer Solution Preparation and Conductimetric Analysis}

Either PLA-PCL (70:30) or PLGA (82:18) were dissolved in DCM at 20\% $(w / v)$, and they were maintained under magnetic stirring at $100 \mathrm{rpm}$ in an ice bath. After being weighed, the amount of VMC was stored in a sealed vial and then dispersed in acetone. VMC dispersion was carried out by magnetic stirring in an ice bath to prevent solvent evaporation and drug degradation. The VMC suspension was added, drop by drop, to the polymeric solution, and it was maintained under magnetic stirring for $30 \mathrm{~min}$ in an ice bath. Different solvent systems were prepared to suspend VMC and dissolve PLA-PCL and PLGA. DCM/acetone at ratios were 80:20, 70:30, and 60:40 $(15 \%, w / v)$. Since VMC was slightly soluble in the polymeric solution and it was mostly suspended, Span ${ }^{\circledR} 80$ at $0.05 \% v / v$ was added to stabilize the suspension.

The conductimetric analysis was carried out with the laboratory conductometer (914 pH/conductometer, $\Omega$ Metrohm AG, CH-9 100 Herisau, Switzerland) equipped with a conductivity probe specific for organic solvent. 


\subsubsection{Preparation of Tubular Vascular Grafts}

Electrospun tubular vascular grafts loaded with VMC (VTVGs) were prepared using GMP-oriented electrospinning (NANON 01A Electrospinning setup, MECC Co). The process was carried out at atmospheric pressure, maintaining the room and instrument chamber at $28 \pm 2{ }^{\circ} \mathrm{C}$ with relative humidity of about $25 \pm 5 \%$. Humidity was controlled thanks to a dehumidifier instrument connected to electrospinning; room temperature was set with autonomous heating. Electrospinning process parameters were selected in a preliminary screening (data not reported) and are summarized in Table 1.

Table 1. Electrospinning process parameters.

\begin{tabular}{|c|c|c|}
\hline \multicolumn{2}{|c|}{ Parameters } & Set Up \\
\hline \multirow{3}{*}{ Spindle } & Nozzle-collector distance (mm) & 150 \\
\hline & Rotating mandrel diameter (mm) & 6 \\
\hline & Mandrel rotation speed (rpm) & 2500 \\
\hline \multirow{2}{*}{ Spinneret } & Speed $(\mathrm{mm} / \mathrm{s})$ & 50 \\
\hline & Width (mm) & 50 \\
\hline \multirow{3}{*}{ Cleaning } & Frequency (s) & 60 \\
\hline & Time (s) & 1 \\
\hline & Voltage $(\mathrm{kV})$ & 30 \\
\hline \multirow{2}{*}{ Syringe } & Flow rate $(\mathrm{mL} / \mathrm{h})$ & 5 \\
\hline & Nozzle diameter (gauge) & 18 and 22 \\
\hline Electrospinning time & $\min$ & 7 \\
\hline
\end{tabular}

Electrospinning time was fixed at $7 \mathrm{~min}$ in order to obtain a uniform monolayer graft; voltage, flow rate, and nozzle diameter were modified through different electrospinning procedures in order to define the best setup. The electrospun samples were recovered from the collector and were weighted; then, an electronic digital caliper measured their wall thickness. Grafts were set on plastic straw to preserve their structure and were stored at $4.0 \pm 1.0^{\circ} \mathrm{C}$ until further characterization.

\subsubsection{Tubular Vascular Grafts Characterization}

\section{Morphometric Analysis}

Morphologic characterization was carried out by scanning electron microscopy (SEM). VTVGs samples were cut appropriately into squares of $0.5 \times 0.5 \mathrm{~cm}$; each sample was fixed on carbon supports and it was covered with a gold layer. All samples were observed at different magnifications $(500 \mathrm{X}, 3.0 \mathrm{kX}, 10 \mathrm{kX}$, and $30 \mathrm{kX})$ and accelerated voltages $(20 \mathrm{kV})$ in high vacuum at room temperature by scanning electron microscope (SEM) Zeiss EVO MA 10 (Carl Zeiss, Oberkochen Germany).

Wettability Evaluation

Wettability was estimated through contact angle (CA) measurement. The wettability was measured on VTVGs and placebo TVGs using phosphate saline buffer (pH 7.4) with the aim of evaluating VTVG composition on graft wettability. The test was performed by Contact Angle Meter Dme-211 (Kiowa Interface Science co., Ldt., Hongo, Japan), equipped with a glass syringe with needle, a base where glass slide is located with sample, a light source, and the camera. The distance between the syringe and the base was fixed at $1 \mathrm{~cm}$, and drop volume was at 3-4 $\mu \mathrm{L}$. 


\section{Fluid Uptake Capability}

Fluid uptake capability was determined gravimetrically on all prototypes; the test was carried out on a section cut in circular shapes with a diameter of about $1.9 \mathrm{~cm}$. The samples were fixed into cell crowns, and $4 \mathrm{~mL}$ PBS pH 7.4 was added into the well to embed them; all samples were incubated in static conditions at $37^{\circ} \mathrm{C}$. At scheduled times $(2,4,6,24$, and $48 \mathrm{~h}$ ), each cell crown was taken out from the well and weighed after the removal of the water surplus by dripping. The fluid uptake's percentage, FU (\%) was calculated using Equation (1):

$$
\mathrm{FU}(\%)=\left(\mathrm{M}_{\mathrm{n}}-\mathrm{M}_{0}\right) / \mathrm{M} 0 * 100,
$$

where $M_{n}$ is the mass at different time soaking and $M_{0}$ is the mass at time zero when samples were dry.

Drug Content and Encapsulation Efficiency Determination

VMC drug content (DC) and encapsulation efficiency (EE, \%) were determined for each prototype. All samples were prepared by cutting each graft in three distinctive square parts $(1 \times 1 \mathrm{~cm})$; each sample was weighted, put in plastic tubes, and dissolved in DCM $(1 \mathrm{~mL})$. VMC hydrochloride was extracted from DCM suspension by addition of water $(1 \mathrm{~mL})$. VMC extraction protocol was set up and validated, giving VMC $95.30 \pm 3.7 \%$ extraction percentage. The quantification of VMC was performed by HPLC following the protocol reported in Section 2.2.1. (preformulation study-HPLC analysis). The HPLC analysis was carried out in triplicate for each sample, and DC and EE values were expressed as average \pm standard deviation. Drug content was expressed in $\mu \mathrm{g} / \mathrm{mg}$ and was calculated by Equation (2):

$$
\mathrm{DC}=\mathrm{VMC} \text { actually in the sample }(\mu \mathrm{g}) / \text { sample weight },
$$

The encapsulation efficiency percentage was determined using Equation (3), wherein the theoretical mass of VMC was determined by Equation (4), starting from the knowledge that the drug loaded in the polymeric solution is the $5 \%$ of the polymer's mass, expressed by samples mass.

$$
\mathrm{EE}(\%)=[\mathrm{VMC} \text { Actual mass } / \mathrm{VMC} \text { theoretical mass of VMC }] * 100 \text {, }
$$

Theoretical mass of VMC $(\mu \mathrm{g})=(5 *$ mass of sample $) / 100$,

In Vitro Release Study

VMC release test was performed in a time lapse of $96 \mathrm{~h}$ on all grafts in order to assess how graft composition could affect VMC release profile. The samples were prepared by cutting each graft in circular sample with $1.9 \mathrm{~cm}$ diameter; all samples were weighted and then fixed into cell crowns, set in a 12-multi-well. Following, they were dipped in $2 \mathrm{~mL}$ of PBS (pH 7.4) and incubated in static conditions at $37^{\circ} \mathrm{C}$.

At scheduled times $(2,4,6,24,48,72$, and $96 \mathrm{~h}), 1 \mathrm{~mL}$ of PBS was withdrawn from each well and diluted (1:10) with HPLC mobile phase; the PBS was replaced with fresh PBS $(1 \mathrm{~mL})$. pH of incubation medium was measured along the test in order to evaluate possible $\mathrm{pH}$ shifts (827 $\mathrm{pH}$ lab $\mathrm{pH}-$ meter, Methron ion analysis, Switzerland).

\section{Results and Discussion}

VWC solubility in water was around $>100 \mathrm{mg} / \mathrm{mL}$ and it did not vary with test temperature. The solubility of VMC in PBS, at $\mathrm{pH} 7.4$, was $\approx 6$ orders of magnitude lower than that in water.

Although VMC is slightly soluble in DCM, acetone, and solvent system in terms of $\mathrm{DCM}$ /acetone (70:30) $(<1.50 \mathrm{mg} / \mathrm{mL})$, its solubility slightly increased in $\mathrm{MeOH}(5.7 \mathrm{mg} / \mathrm{mL})$. VMC solutions were stable for 7 days in refrigerated conditions and protected from light, indicating their good stability. In the photo-stability study, conducted at 22 and $34{ }^{\circ} \mathrm{C}$, 
evidence of VMC degradation during exposure to visible light for 7 days was observed (data not shown).

Conductivity results are summarized in Table 2 . The conductivity values depended on solution composition; it was expected to increase as long as acetone content increased, considering good conductivity of acetone $(0.472 \mathrm{mS} / \mathrm{cm})$ compared with the conductivity of DCM $(0.01 \mathrm{mS} / \mathrm{cm})$.

The highest values of conductivity were observed for DCM/acetone 70:30 ratio, which corresponded to an intermediate amount of acetone in the considered solvent systems. The highest conductivity values were measured with the addition of VMC, reaching 3.274 and $0.770 \mathrm{mS} / \mathrm{cm}$, respectively, for VTVG7 and VTVG19.

Table 2. Composition of VTVG formulations, conductivity values, and morphology of electrospun fiber.

\begin{tabular}{|c|c|c|c|c|c|}
\hline \multirow{2}{*}{ Formulation No. } & \multicolumn{3}{|c|}{ Composition } & \multirow{2}{*}{$\begin{array}{l}\text { Conductivity } \\
(\mathrm{mS} / \mathrm{cm})\end{array}$} & \multirow{2}{*}{$\begin{array}{l}\text { Electrospun Fiber } \\
\text { Morphology * }\end{array}$} \\
\hline & $\operatorname{VMC}(w / v \%)$ & Surfactant $(v / v \%)$ & DCM/Acetone Ratio (v/v) & & \\
\hline \multicolumn{6}{|c|}{ PLA-PCL $15 \% w / v$} \\
\hline VTVG1 & - & - & $80: 20$ & 0.095 & - \\
\hline VTVG2 & - & 0.05 & $80: 20$ & 0.128 & $+1-$ \\
\hline VTVG3 & 5 & - & $80: 20$ & 0.568 & $+1-\hat{\imath}$ \\
\hline VTVG4 & 5 & 0.05 & $80: 20$ & 0.174 & $+/-$ \\
\hline VTVG5 & - & - & $70: 30$ & 1.892 & - \\
\hline VTVG6 & - & 0.05 & $70: 30$ & 1.784 & + \\
\hline VTVG7 & 5 & - & $70: 30$ & 3.274 & $+\wedge$ \\
\hline VTVG8 & 5 & 0.05 & $70: 30$ & 2.220 & + \\
\hline VTVG9 & - & - & $60: 40$ & 0.500 & - \\
\hline VTVG10 & - & 0.05 & $60: 40$ & 1.076 & $+/-$ \\
\hline VTVG11 & 5 & - & $60: 40$ & 0.844 & $+/-\hat{\imath}$ \\
\hline VTVG12 & 5 & 0.05 & $60: 40$ & 2.855 & $+/-$ \\
\hline \multicolumn{6}{|c|}{ PLGA $15 \% w / v$} \\
\hline VTVG13 & - & - & $80: 20$ & 0.033 & $+1-$ \\
\hline VTVG14 & - & 0.05 & $80: 20$ & 0.045 & $+1-$ \\
\hline VTVG15 & 5 & - & $80: 20$ & 0.086 & $+/-\hat{\imath}$ \\
\hline VTVG16 & 5 & 0.05 & $80: 20$ & 0.174 & $+/-$ \\
\hline VTVG17 & - & - & $70: 30$ & 0.595 & $+1-$ \\
\hline VTVG18 & - & 0.05 & $70: 30$ & 0.225 & + \\
\hline VTVG19 & 5 & - & $70: 30$ & 0.770 & $+/-\hat{\imath}$ \\
\hline VTVG20 & 5 & 0.05 & $70: 30$ & 0.659 & + \\
\hline VTVG21 & - & - & $60: 40$ & 0.308 & $+1-$ \\
\hline VTVG22 & - & 0.05 & $60: 40$ & 0.176 & $+1-$ \\
\hline VTVG23 & 5 & - & $60: 40$ & 0.032 & $+/-\hat{\imath}$ \\
\hline VTVG24 & 5 & 0.05 & $60: 40$ & 0.446 & + \\
\hline
\end{tabular}

+ regular fibers; - irregular fibers beads forming; +/- irregular flattered fibers; ${ }^{\wedge}$ VMC precipitation. * from SEM images.

The formulations containing both VMC and surfactant (VTVG8 and VTVG20) showed an increment of solution conductivity compared to their polymer solution (VTVG5 and VTVG20); nevertheless, their values $(2.220$ and $0.659 \mathrm{mS} / \mathrm{cm})$ were lower than results associated to formulation obtained with the addition of only VMV (VTVG7, VTVG19). These high conductivity values led to small size fibers $(<2 \mu \mathrm{m})$, particularly for VTVG8 and VTVG20; considering the electrospun fiber morphology evidences, the most promising results, in terms of electrospinnability and fiber homogeneity, were found for protorypes containg VMC and surfactant.

The organic solvent selected for preparing polymer solution containing VMC was the solvent system based on DCM and acetone at different ratios (80:20, 70:30, and 60:40 v/s). Acetone was identified as the most compatible organic solvent for dissolving both polymer and active agent (VMC); DCM was mixed with acetone to increment evaporation rate of 
pure acetone. The evaporation rate of an organic solvent was defined as the rate at which it vaporizes compared to the rate of vaporization of n-butyl acetate (1.0), generally used as reference material for evaporation rate. Acetone evaporation rate compared to n-butyl acetate was 5.6, while DCM was 27.5. The evaporation rate of their mixture depends on solvent ratio and is between these two values. The evaporation of solvent of liquid jet during electrospinning process is a critical step affecting electrospun matrix morphology and their in vitro and in vivo performances.

The percentage of $\mathrm{VMC}$, to add into polymer solution, was set up at $5 \% w / v$; this value was defined on the basis of VMC solubility in polymer solutions, and concentrations below $5 \% w / v$ were not taken in consideration, owing to the need of reaching VMC minimum inhibitory concentration (MIC $2 \mu \mathrm{g} / \mathrm{mL}$ ).

Span80 was added to formulation for improving VMC apparent solubility and its stability in the polymer solutions during the electrospinning process. The percentage of Span80 was defined considering the acceptable daily intake of that surfactant $(25 \mathrm{mg} / \mathrm{kg})$, as determined by the World Health Organization (WHO) [31].

Table 3 reports the results of electrospun matrix characterization in terms of fiber morphology depending on solution composition, solvent system ratio, and conductivity value. The solvent system at the ratio of 70:30 was the most suitable to be electrospun, and the most promising results were achieved when surfactant and active agent were included in polymer solution. In Figures 2 and 3, representative SEM images are shown, wherein micrographs of formulation placebo (VTVG5 and 17) were not uniform in terms of size and size distribution (Figures 2a and 3a); the addition of surfactant (VTVG6) allowed us to obtain regular fibers, well interconnected and with narrow size distribution, $0.23-5.62 \pm 0.99$ (Figures $3 b$ and $4 b$ ).

Table 3. Fiber characterization by SEM ImageJ processing.

\begin{tabular}{|c|c|c|c|c|c|c|}
\hline $\begin{array}{c}\text { Formulation } \\
\text { No. }\end{array}$ & $\begin{array}{c}\text { Fiber Diameter } \\
\text { Range } \\
(\mu \mathrm{m})\end{array}$ & $\begin{array}{l}\text { Nano-Sized } \\
\text { Fiber }(\%)\end{array}$ & $\begin{array}{c}\text { High- } \\
\text { Frequency } \\
\text { Orientation }\left({ }^{\circ}\right)\end{array}$ & Porosity $(\% \pm$ SD) & $\begin{array}{c}\text { Number of } \\
\text { Pores }\end{array}$ & $\begin{array}{c}\text { Pore Area } \\
\text { Range }\left(\mu \mathrm{m}^{2}\right)\end{array}$ \\
\hline VTVG5 & $0.22-9.08 \pm 0.59$ & 10.4 & $+45^{\circ}$ & $55 \pm 2.1$ & 120.33 & $0.15-504.06$ \\
\hline VTVG6 & $0.23-5.62 \pm 0.99$ & 4.0 & $+1^{\circ}$ & $49 \pm 3.0$ & 75.00 & $0.19-218.80$ \\
\hline VTVG7 & $0.23-5.23 \pm 0.72$ & 7.2 & $+44^{\circ}$ & $56 \pm 3.5$ & 161.34 & $0.16-251.52$ \\
\hline VTVG8 & $0.21-7.37 \pm 0.90$ & 5.2 & $+4^{\circ}$ & $40 \pm 1.3$ & 86.33 & $0.23-240.68$ \\
\hline VTVG17 & $0.21-7.59 \pm 0.82$ & 4.7 & $-87^{\circ}$ & $50 \pm 2.1$ & 82.33 & $0.22-228.76$ \\
\hline VTVG18 & $0.21-6.32 \pm 0.88$ & 6.3 & $+88^{\circ}$ & $49 \pm 2.3$ & 100.33 & $0.16-279.28$ \\
\hline VTVG19 & $0.23-8.70 \pm 1.14$ & 4.8 & $-9^{\circ}$ & $46 \pm 2.6$ & 89.67 & $0.18-178.91$ \\
\hline VTVG20 & $0.21-7.79 \pm 1.89$ & 4.4 & $-89^{\circ}$ & $39 \pm 1.5$ & 49.33 & $0.15-183.02$ \\
\hline
\end{tabular}

For VTVG7, incorporation of the active agent led to a further reduction of fiber size $(0.23-5.23 \pm 0.72 \mu \mathrm{m}) ; 7.2 \%$ nanosized fibers were detected by ImageJ analysis in VTVG7, and the decrement in fiber diameter was put down to high conductivity of solution $(3.274 \mathrm{mS} / \mathrm{cm})$. Magnification at $10 \mathrm{kX}$ pointed out aggregates on fiber surface (Figure $2 \mathrm{c}$ ) that were ascribed to inefficient incorporation of VMC into fibers and its precipitation during solvent evaporation.

Concomitant addition of surfactant and active agent allowed for a significant reduction of VMC aggregates on fiber surfaces (Figure 3d) and the production of more regular fibers with smaller diameter. The result can be attributable to high conductivity value of polymer solution (VTVG8, $2.220 \mathrm{mS} / \mathrm{cm}$ ) as well as to increased apparent solubility of active agent in polymer solution as a consequence of surfactant inclusion in formulation.

SEM micrographs of PLGA VTVGs (Figure 2a) showed poor homogeneous fibers, and addition of surfactant promoted fiber orientation, as shown in Figure $4 b$,d. The result was confirmed by the orientation data reported in Table 3, and VTVG18 and VTVG20 showed a frequency orientation of $+88^{\circ}$ and $-89^{\circ}$, respectively. 

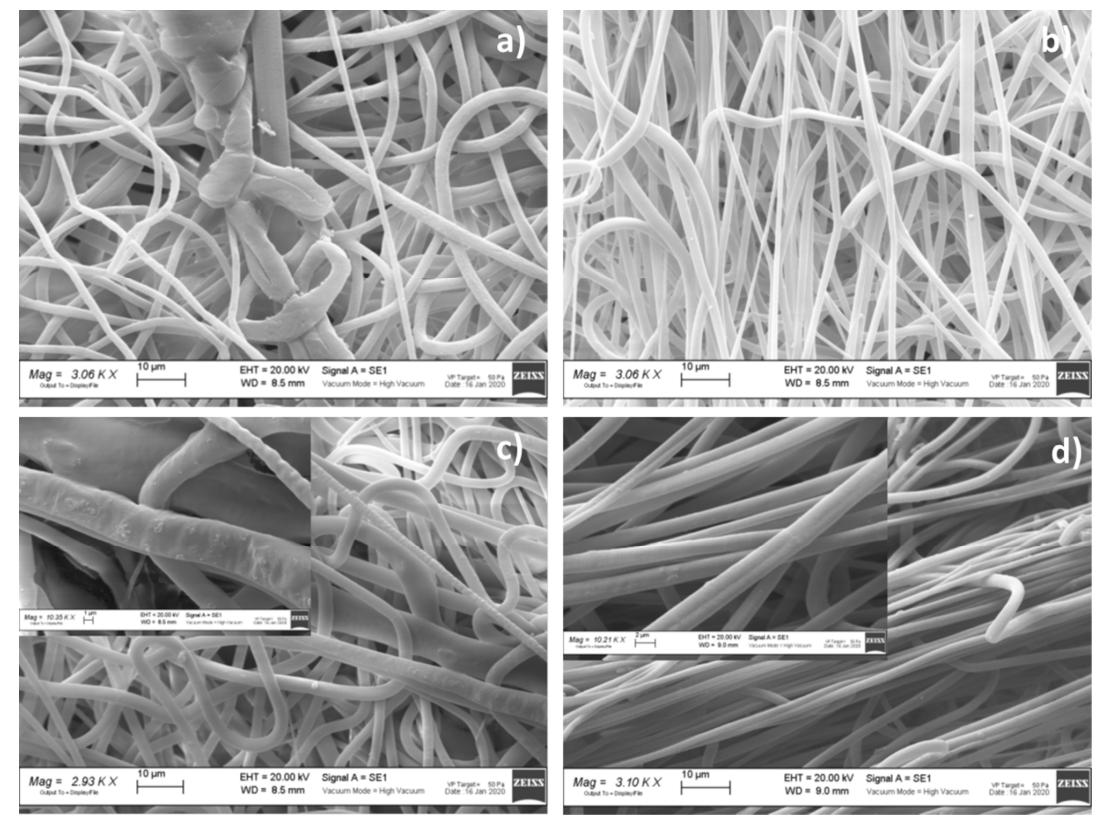

Figure 3. SEM images of (a) VTVG17; (b) VTVG18; (c) VTVG19; (d) VTVG20. Insert shows 10 kX magnification images.

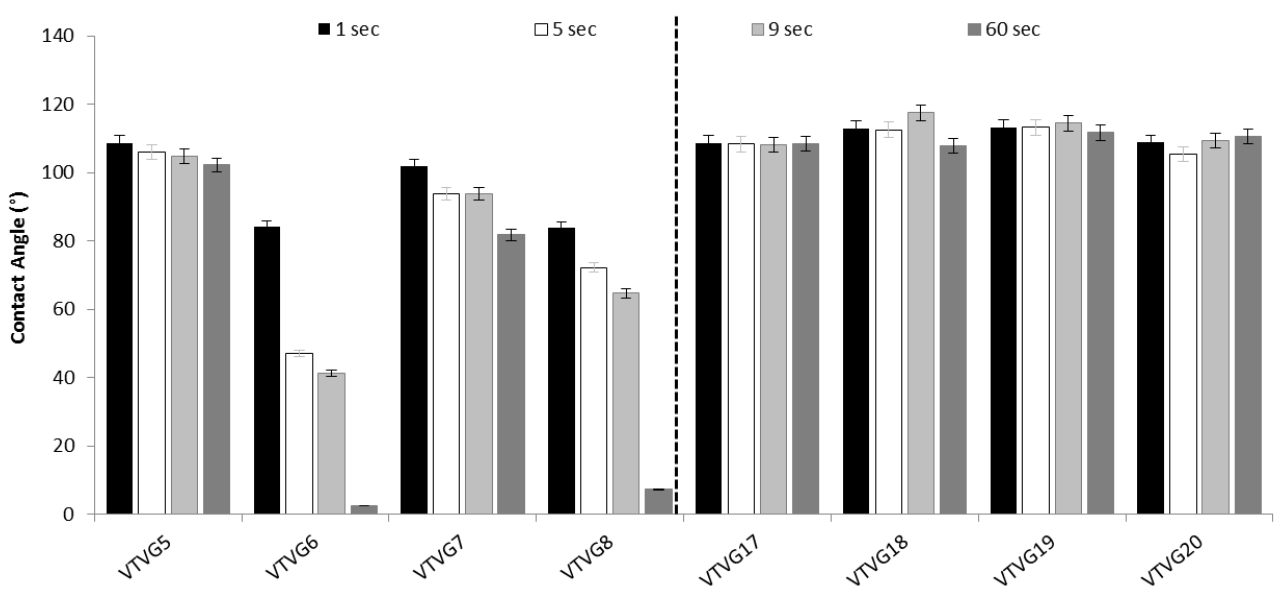

Figure 4. Contact angle and absorption kinetic of PLA-PCL and PLGA VTVGs. Data are expressed as average \pm standard deviation $(n=6)$.

Concomitant addition of surfactant and active agent allowed for a significant reduction of VMC aggregates on fiber surfaces (Figure 2d) and the production of more regular fibers with smaller diameter. The result can be attributable to high conductivity value of polymer solution (VTVG8, $2.220 \mathrm{mS} / \mathrm{cm}$ ) as well as to increased apparent solubility of active agent in polymer solution as consequence of surfactant inclusion in formulation.

Porosity percentage, number of pores, and pore area range are collected in Table 3 for all formulations. The porosity percentage was between $46 \%$ and $54 \%$, and it was reduced, for both polymers meshes, after surfactant addition (VTVG6 and VTVG18) and after addition of active agent (VTVG7 and VTVG19).

Samples prepared through incorporating both surfactant and active agent (VTVG8 and VTVG20) did not show significant variation in porosity percentage with respect to those loaded with either surfactant or active agent. Consistently, the number of pores were lower and mean pore area was higher with the addition of the surfactant (VTVG6 and VTVG18) with respect to formulations of VTVG5 and VTVG17; intermediate values are shown by prototypes obtained through incorporating surfactant and active agent (VTVG8 
and VTVG20). Finally, surfactant addition caused, for all analyzed samples, pore area range reduction and a mean pore area $\left(\mu \mathrm{m}^{2}\right)$ increment. Results of porosity led to the conclusion that surfactant is fundamental for obtaining fibers more regular in size and with broad pore distribution. Moreover, VTVGs based on PLGA (VTVGs 17-20) showed smaller mean pore area with respect to those based on PLA-PCL (VTVGs 5-8), presenting a denser fiber network.

Contact angle results were plotted as a histogram in Figure 4. It is clearly shown that graft composition affected both contact angle and drop absorption kinetic, particularly as far as PLA-PCL VTVGs is concerned. Contact angle of VTVG5 and VTVG17 were identical $\left(108.8^{\circ}\right)$, and this value was maintained constant over the time for formulations based on PLGA (VTVG17-20, data not reported). This evidence could be also due to the dense PLGA network, highlighted with SEM, which contains fluid diffusion into fiber network. Contact angle values of VTVGs based on PLA-PCL polymer, in contrast, were influenced by addition of surfactant in the formulations (VTVG 6 and 8), with significant decrease reaching values $<10^{\circ}$ after $60 \mathrm{~s}$.

Fluid uptake results showed that PLA-PCL electrospun fibers (VTVG5-8) had higher fluid uptake capability than PLGA fibers and exhibited good stability during all incubation times (48 h) (Figure 5). This behavior was consistent with PLGA graft high contact angle values (VTVGs 17-20) and it was attributed to transition temperature ( $T g$ ) values of polymers as well as to fiber mat density. Considering $\mathrm{Tg}$ values, PLA-PCL has a $\mathrm{Tg}$ at $37^{\circ} \mathrm{C}$ and it was almost in a rubbery state when embedded in PBS at $37^{\circ} \mathrm{C}$ by conferring good mobility to PLC-PCL chains and facilitating fluid diffusion. On the contrary, PLGA polymer $\mathrm{Tg}$ ranged from 50 to $60{ }^{\circ} \mathrm{C}$, providing a more rigid conformation that constrained fluid uptake and diffusion. Furthermore, as previously highlighted by SEM characterization, PLGA showed high fiber density with respect to that of PLA-PCL electrospun matrices. By comparing PLA-PCL grafts (VTVG5-8), we detected the most significant difference for VTVG6 and VTVG8 prototype based on PLA-PCL supplemented with surfactant; for both, the results revealed limited fluid uptake capability with respect to VTVG5 and VTVG9 formulations, which were formulated with no surfactant. This evidence could be explained by the surfactant influence on fiber size and size distribution; as previously observed by SEM analysis, the surfactant incorporation allowed us to achieve regular fibers, well interconnected and with narrow size distribution determining a denser matrix. The fluid uptake capability of formulations based on PLGA was limited compared with VTVG5-8 formulations, reaching almost 90\% uptake after incubation for $24 \mathrm{~h}$ (VTVG17); a more constrained uptake was highlighted for all VTVG18-20.
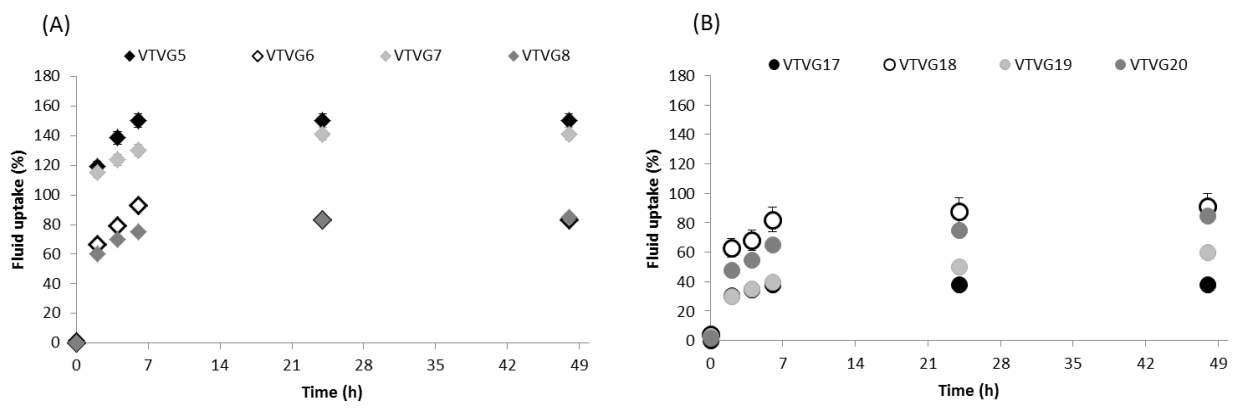

Figure 5. Fluid uptake capability of VTVGs vs. time $(n=3)$. VTVGs formulation based on PLA-PCL (A) and PLGA (B) polymers.

VMC EE \% calculated on the whole VTVG ranged between $76.37 \%$ and $82.26 \%$. Total drug content, expressed as milligram per graft $(40 \mathrm{mg})$, was about $1.5 \pm 0.5 \mathrm{mg}$ / formulation. Considering formulation based on PLA-PCL, formulation VTVG8 (prepared with addition of surfactant) showed a reduced release at the second hour $(0.30 \pm 0.006 \%)$, reaching $20 \%$ after six hours; no further release was detected within the 24 th hour (Figure 6a). A gradual and rapid release of VMC was measured over the next three days; $90 \%$ of VMC was released after $96 \mathrm{~h}$, and this behavior was justified considering VTVG7 high porosity, 
large number of pores, and its extensive fluid uptake with respect to VTVG8 (Table 3, Figure 5a).
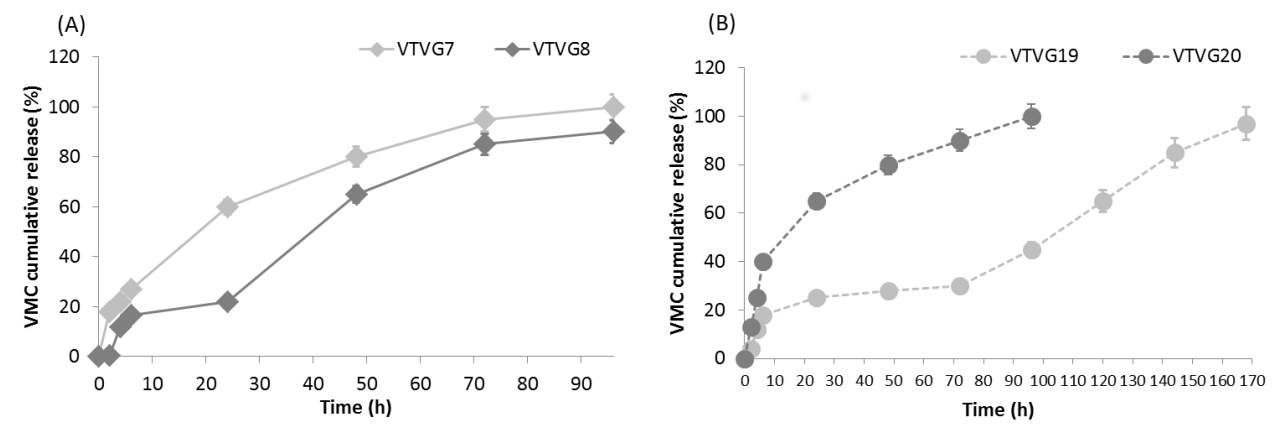

Figure 6. In vitro release study of VTVGs incorporating VMC; data are expressed as percentage of VMC released vs. time $(n=3)$. VTVG formulation was based on PLA-PCL polymer (A) and PLGA polymer (B).

VTVG7 formulations showed a prompt release of VMC; burst release at the sixth hour was at $27 \%$, followed up by a more consistent release compared with VTVG8. The high burst release was ascribed to surfactant; as previously supposed, the surfactant enhanced the solubilization of VMC into polymer solution and its dispersion into electrospun fibers, avoiding any precipitation phenomena on the fiber surface. Indeed, VMC was incorporated properly, and no evidence of VMC precipitate was detected by SEM analysis (Figure 2d). This burst release of VTVG7 was followed by a fast release of VMC, catching up 95\% within the 72nd hour.

PLGA formulations (VTVG19 and 20) released on average 21\% of VMC within the first $6 \mathrm{~h}$, regardless of formulation composition (Figure $6 \mathrm{~b}$ ). An increase between the 6th and 24th hours was evident, and then a more gradual release was achieved, reaching $100 \%$ at the 96th hour. VTVG19 showed a peculiar release with a slight release of VMC between the 4 th and 72nd, hour followed by a more rapid and gradual release; $100 \%$ of release was achieved in $168 \mathrm{~h}$. The release profiles of PLGA formulations were in line with porosity percentage and their restricted capability to uptake fluid (Figure 5b); in fact, a restricted uptake of fluid was measured for VTVG20.

Finally, differences in release profiles between PLA-PCL and PLGA grafts can be ascribed to specific composition of formulations, as well as their structure with regard to porosity, number of pores, pore area range, and volume of fluid going through the fibers.

$\mathrm{pH}$ values of incubation medium during in vitro release study ranged between 7.29 and 7.35 (data not reported), demonstrating that neither VMC acidic behavior nor possible degradation polymeric byproducts impacted the medium $\mathrm{pH}$.

\section{Conclusions}

PLA-PCL and PLGA tubular grafts could provide a promising alternative to existing non-degradable grafts. Through the use of synthetic polymers and the electrospinning technology, biodegradable and biocompatible tubular graft, sized $<6 \mathrm{~mm}$, can be produced with peculiar features, including hydrophilicity and fluid absorbency; surfactant addition into polymer solutions resulted in being crucial for obtaining small size and uniform fibers, as well as for incorporating VMC uniformly into polymer fibers. PLA-PCL and PLGA tubular grafts thus offer improvements over synthetic grafts in terms of biodegradability, graft capability of entrapping fluids, and control of antibiotic release over the time beyond VMC minimum inhibitory concentration (MIC, $2 \mu \mathrm{g} / \mathrm{mL}$ ).

PLA-PCL favorably compares to PLGA in terms of fluid uptake capability, as demonstrated by wettability evaluation and in vitro uptake study over the period of up to 3 days, whereas the PLGA vascular grafts showed a strong hydrophobic character and limited fluid uptake capability. In addition, a controlled release of VMC was observed for formulation 
based on PLA-PCL and containing surfactant, as a reduced burst release followed by a more regular release of vancomycin over time.

While these results are promising, future studies will be essential to evaluate the cell response and compliance at the site of implantation, radial extension, overall mechanical features, and degradation rate.

Author Contributions: Conceptualization, R.D.; methodology, E.C.; formal analysis, M.R., G.B.; investigation, S.P., R.D.; data curation, M.R., R.D.; writing-original draft preparation, M.R., E.C.; writing-review and editing, R.D., B.C.; visualization, T.M.; supervision, B.C.; project administration, I.G. All authors have read and agreed to the published version of the manuscript.

Funding: This research received no external funding.

Institutional Review Board Statement: Not Applicable.

Informed Consent Statement: Not Applicable.

Data Availability Statement: Not Applicable.

Conflicts of Interest: The authors declare no conflict of interest.

\section{References}

1. Gutowski, P.; Gage, S.; Guziewicz, M.; Ilzecki, M.; Kazimierczak, A.; Kirkton, R.D.; Niklason, L.E.; Pilgrim, A.; Prichard, H.L.; Przywara, S.; et al. Arterial reconstruction with human bioengineered acellular blood vessels in patients with peripheral arterial disease. J. Vasc. Surg. 2020, 72, 1247-1258. [CrossRef] [PubMed]

2. Liu, K.S.; Lee, C.H.; Wang, Y.C.; Liu, S.J. Sustained release of vancomycin from novel biodegradable nano-fiber-loaded vascular prosthetic grafts: In vitro and in vivo study. Int. J. Nanomed. 2015, 10, 885-891. [CrossRef] [PubMed]

3. Almasri, J.; Adusumalli, J.; Asi, N.; Lakis, S.; Alsawas, M.; Prokop, L.J.; Bradbury, A.; Kolh, P.; Conte, M.S.; Murad, M.H. A systematic review and meta-analysis of revascularization outcomes of infrainguinal chronic limb-threatening ischemia. J. Vasc. Surg. 2018, 68, 624-633. [CrossRef]

4. Ong, C.S.; Zhou, X.; Huang, C.Y.; Fukunishi, T.; Zhang, H.; Hibino, N. Tissue engineered vascular grafts: Current state of the field. Expert Rev. Med. Devices 2017, 14, 383-392. [CrossRef]

5. Pan, Y.; Zhou, X.; Wei, Y.; Zhang, Q.; Wang, T.; Zhu, M.; Li, W.; Huang, R.; Liu, R.; Chen, J.; et al. Small-diameter hybrid vascular grafts composed of polycaprolactone and polydioxanone fibers. Sci. Rep. 2017, 7, 3615. [CrossRef]

6. Catto, V.; Farè, S.; Cattaneo, I.; Figliuzzi, M.; Alessandrino, A.; Freddi, G.; Remuzzi, A.; Tanzi, M.C. Small diameter elec-trospun silk fibroin vascular grafts: Mechanical properties, in vitro biodegradability, and in vivo biocompatibility. Mater. Sci. Eng. C 2015, 54, 101-111. [CrossRef] [PubMed]

7. Fukunishi, T.; Best, C.A.; Sugiura, T.; Shoji, T.; Yi, T.; Udelsman, B.; Ohst, D.; Ong, C.S.; Zhang, H.; Shinoka, T.; et al. TissueEngineered Small Diameter Arterial Vascular Grafts from Cell-Free Nanofiber PCL/Chitosan Scaffolds in a Sheep Model. PLoS ONE 2016, 11, e0158555. [CrossRef] [PubMed]

8. Pashneh-Tala, S.; MacNeil, S.; Claeyssens, F. The Tissue-Engineered Vascular Graft-Past, Present, and Future. Tissue Eng. Part B Rev. 2016, 22, 68-100. [CrossRef] [PubMed]

9. Matsuzaki, Y.; John, K.; Shoji, T.; Shinoka, T. The Evolution of Tissue Engineered Vascular Graft Technologies: From Preclinical Trials to Advancing Patient Care. Appl. Sci. 2019, 9, 1274. [CrossRef]

10. Yuan, H.; Chen, C.; Liu, Y.; Lu, T.; Wu, Z. Strategies in cell-free tissue-engineered vascular grafts. J. Biomed. Mater. Res. Part A 2020, 108, 426-445. [CrossRef]

11. Cordelle, J.; Mantero, S. Insight on the endothelialization of small silk-based tissue-engineered vascular grafts. Int. J. Artif. Organs 2020, 43, 631-644. [CrossRef] [PubMed]

12. Drews, J.D.; Pepper, V.K.; Best, C.A.; Szafron, J.M.; Cheatham, J.P.; Yates, A.R.; Hor, K.N.; Zbinden, J.C.; Chang, Y.-C.; Mirhaidari, G.J.M.; et al. Spontaneous reversal of stenosis in tissue-engineered vascular grafts. Sci. Transl. Med. 2020, 12, eaax6919. [CrossRef]

13. Dreyfus, J.; Begier, E.; Yu, H.; Quintana, A.; Gayle, J.; Olsen, M.A. 1228. Incidence of Staphylococcus aureus Infection after Elective Surgeries Among Adults in US Hospitals. Open Forum Infect. Dis. 2018, 5, S372-S373. [CrossRef]

14. Dorati, R.; DeTrizio, A.; Spalla, M.; Migliavacca, R.; Pagani, L.; Pisani, S.; Chiesa, E.; Conti, B.; Modena, T.; Genta, I. Gen-tamicin Sulfate PEG-PLGA/PLGA-H Nanoparticles: Screening Design and Antimicrobial Effect Evaluation toward Clinic Bacterial Isolates. Nanomaterials 2018, 8, 37. [CrossRef]

15. Pisani, S.; Dorati, R.; Chiesa, E.; Genta, I.; Modena, T.; Bruni, G.; Grisoli, P.; Conti, B. Release Profile of Gentamicin Sulfate from Polylactide-co-Polycaprolactone Electrospun Nanofiber Matrices. Pharmaceutics 2019, 11, 161. [CrossRef] [PubMed]

16. Dorati, R.; De Trizio, A.; Genta, I.; Merelli, A.; Modena, T.; Conti, B. Gentamicin-Loaded Thermosetting Hydrogel and Moldable Composite Scaffold: Formulation Study and Biologic Evaluation. J. Pharm. Sci. 2017, 106, 1596-1607. [CrossRef] [PubMed] 
17. Zhai, W.; Qiu, L.J.; Mo, X.M.; Wang, S.; Xu, Y.F.; Peng, B.; Liu, M.; Huang, J.H.; Wang, G.C.; Zheng, J.H. Coaxial electro-spinning of P(LLA-CL)/heparin biodegradable polymer nanofibers: Potential vascular graft for substitution of femoral artery. J. Biomed. Mater. Res. Part B 2019, 107, 471-478. [CrossRef]

18. Chen, D.; Zhang, L.; Zhang, W.; Tang, Z.; Fu, W.; Hu, R.; Feng, B.; Hong, H.; Zhang, H. Shapeable large-pore electrospun polycaprolactam cotton facilitates the rapid formation of a functional tissue engineered vascular graft. Mater. Des. 2020, 191, 108631. [CrossRef]

19. Huang, A.H.; Niklason, L.E. Engineering Biological-Based Vascular Grafts Using a Pulsatile Bioreactor. J. Vis. Exp. 2011, 52, e2646. [CrossRef]

20. Hu, Q.; Su, C.; Zeng, Z.; Zhang, H.; Feng, R.; Feng, J.; Li, S. Fabrication of multilayer tubular scaffolds with aligned nan-ofibers to guide the growth of endothelial cells. J. Biomater. Appl. 2020, 35, 553-566. [CrossRef]

21. Joy, J.; Aid-Launais, R.; Pereira, J.; Pavon-Djavid, G.; Ray, A.R.; Letourneur, D.; Meddahi-Pellé, A.; Gupta, B. Gela-tinpolytrimethylene carbonate blend based electrospun tubular construct as a potential vascular biomaterial. Mater. Sci. Eng. C 2020, 106, 110178. [CrossRef]

22. Pisani, S.; Dorati, R.; Conti, B.; Modena, T.; Bruni, G.; Genta, I. Design of copolymer PLA-PCL electrospun matrix for biomedical applications. React. Funct. Polym. 2018, 124, 77-89. [CrossRef]

23. Dorati, R.; Chiesa, E.; Pisani, S.; Genta, I.; Modena, T.; Bruni, G.; Brambilla, C.R.; Benazzo, M.; Conti, B. The Effect of Process Parameters on Alignment of Tubular Electrospun Nanofibers for Tissue Regeneration Purposes. J. Drug Deliv. Sci. Technol. 2020, 58, 101781. [CrossRef]

24. Abdullah, K.G.; Attiah, M.A.; Olsen, A.S.; Richardson, A.; Lucas, T.H. Reducing surgical site infections following cra-niotomy: Examination of the use of topical vancomycin. J. Neurosurg. 2015, 123, 1600-1604. [CrossRef] [PubMed]

25. Rubinstein, E.; Keynan, Y. Vancomycin revisited-60 years later. Front. Public Health 2014, 2, 217. [CrossRef] [PubMed]

26. Humphrey, C.; Veve, M.P.; Walker, B.; Shorman, M.A. Long-term vancomycin use had low risk of ototoxicity. PLoS ONE 2019, 14, e0224561. [CrossRef] [PubMed]

27. Zasowski, E.J.; Murray, K.P.; Trinh, T.D.; Finch, N.A.; Pogue, J.M.; Mynatt, R.P.; Rybak, M.J. Identification of Vancomycin Exposure-Toxicity Thresholds in Hospitalized Patients Receiving Intravenous Vancomycin. Antimicrob. Agents Chemother. 2018, 62. [CrossRef]

28. Tseng, Y.Y.; Kao, Y.C.; Liao, J.Y.; Chen, W.A.; Liu, S.J. Biodegradable Drug-Eluting Poly [lactic-co-glycol acid] Nano-fibers for the Sustainable Delivery of Vancomycin to Brain Tissue: In Vitro and in Vivo Studies. ACS Chem. Neuro-Sci. 2013, 4, 1314-1321. [CrossRef]

29. Jang, C.H.; Cho, Y.B.; Jang, Y.S.; Kim, M.S.; Kim, G.H. Antibacterial effect of electrospun polycaprolactone/polyethylene oxide/vancomycin nanofiber mat for prevention of periprosthetic infection and biofilm formation. Int. J. Pediatr. Otorhinolaryngol. 2015, 79, 1299-1305. [CrossRef] [PubMed]

30. Valle, M.J.D.J.; López, F.G.; Navarro, A.S. Development and validation of an HPLC method for vancomycin and its application to a pharmacokinetic study. J. Pharm. Biomed. Anal. 2008, 48, 835-839. [CrossRef]

31. Rowe, R.C.; Sheskey, P.; Quinn, M. Handbook of Pharmaceutical Excipients, 6th ed.; Pharmaceutical Press and American Pharmacists Association; Marcel-Dekker: New York, NY, USA, 2009; ISBN1 978085369792 3. (UK); ISBN2 978158212135 2. (USA). 